\title{
Construction of Blended Teaching Model of Public English in Higher Vocational Colleges Based on Mobile Learning
}

\author{
Gao Zhenfeng \\ Baoji Vocational Technology College, Baoji City, Shaanxi, China, 721013
}

Keywords: Mobile learning; public English in Higher Vocational colleges; blended teaching mode

Abstract: The rise of blended teaching mode has brought new vitality to the development of public English education and teaching. This paper analyses the intrinsic significance of blended English teaching in higher vocational colleges under mobile learning environment, and combines teaching practice, puts forward the key problems of blended English teaching mode for special learning conditions and subject characteristics.

Educational acclimatization is the basic requirement for the development of Higher Vocational education. With the rise of smart phones in the past five years, according to CNNIC (China Internet Information Center) data, as of December 2014, the number of mobile citizens in China reached 557 million, an increase of 56.72 million over 2013. The proportion of Internet users using mobile phones increased from 81.0\% in 2013 to 85.8\%. Among them, the age distribution area accounts for most of the 20-29 years old, and the highest proportion of the occupational structure is student users. Therefore, it is feasible to carry out mobile learning on smart phones in student groups. At the same time, with the decline of the quality of students in recent years, in order to meet the multiple needs of students, it is necessary to combine personalized mobile learning with traditional classroom teaching and build a hybrid teaching mode in mobile learning environment.

\section{The Internal Significance of Mixed Teaching Model}

At present, experts in international educational circles have different research results on Hybrid Teaching mode. They elaborate and analyze the inherent significance and characteristics of hybrid learning from different aspects. However, they all emphasize that various factors should be combined with web-based curriculum learning. Western educational experts understand that hybrid teaching is "to combine various teaching methods with teaching technology organically, aiming at integrating the advantages of online learning and classroom teaching, fully reflecting autonomous learning ability." However, experts in domestic educational circles understand that hybrid teaching is the integration of traditional face-to-face classroom learning and online learning. The curriculum design with diversified characteristics makes curriculum learning no longer subject to time constraints.

However, some experts believe that blended learning is not only a single combination of 
traditional face-to-face learning and online learning, but also an organic combination of many factors. It includes different learning methods, learning conditions, learning subjects and the integration of learning media. Therefore, students can not only learn in the actual classroom, but also use the network platform for online learning; not only can they listen to the teacher's lectures to learn, but also can use the methods of autonomy, cooperation and research to learn; not only can they use books and other printed materials to learn, but also can use video and CD to learn, and other learning methods. In a word, hybrid teaching is the latest teaching mode which combines face-to-face teaching with online learning, and can effectively optimize the diversification of teaching and teaching efficiency

\section{The Main Situation of Public English Teaching in Higher Vocational Colleges}

Due to the weak enrollment of students and teachers in Higher Vocational colleges, most English teachers in higher vocational colleges still adopt the teaching mode of large class teaching in the classroom. When teaching in large classes, the interaction between teachers and students is difficult to fully develop, and teachers are difficult to meet the learning needs of individual knowledge mastery of each student. As for the "student-centered" classroom teaching mode, English teachers seem to be unable to cope with it.

In addition, there are some vocational English teachers whose teaching purpose is to help students pass the English A/B test. Therefore, most of the teaching contents of Vocational English teachers are written teaching related to the examination, lacking the interaction between teachers and students, students can still learn "dumb English", which is difficult to improve studentship application ability. This kind of English teaching method is difficult for students to maintain a good interest in learning, let alone cultivate self-fulfilment ability. Under the current network technology application environment, the traditional face-to-face teaching mode is difficult to adapt to the development of Higher Vocational English teaching. The hybrid teaching mode based on the application of network technology is bound to become a new trend of Higher Vocational English teaching.

3. Key problems of mixed teaching model for special learning situation and subject characteristics in mobile learning environment

3.1 According to the characteristics of Studentship of autonomy, we should strengthen the mixing of learning process and construct a mixed teaching mode of timely tracking and feedback

Higher vocational college students generally have problems such as unbalanced discipline development or bad learning habits in the middle school stage, and they are accustomed to passive learning in the middle school stage. At the University stage, they are not suitable for themselves to be the main body of learning and show strong dependence on learning behavior. For example, at the beginning of the semester from 2015 to 2016-1, the author assigned the first extra-curricular task to 155033/5032/5071/5013 (192 students) in four classes of Nanjing Communications Vocational and Technical College, downloaded 100 words of APP with mobile phones, and checked their vocabulary, asked students to take screen shots and upload them through QQ. One month later, the statistics showed that only 73 students submitted them, with a submission rate of $38 \%$. Two and a half months later, the statistics showed that only 123 people submitted the test results, with a submission rate of $64 \%$. Finally, the test was declared as a sub-item of the normal results, and all the students submitted the test results.

Although the survey sample is too small, it also reflects the common problems of poor autonomy 
and low learning enthusiasm of Higher Vocational students. Therefore, teachers should strengthen the feedback of learning process, change the feedback after learning in the traditional linear learning mode, and strengthen the monitoring, feedback and intervention of all links (pre-eclampsia, in-class and after-class). It is necessary to create a collaborative environment in the first class of freshmen, such as using mobile communication tools such as We Chat, E-mail, QQ, etc., to establish learning groups to realize pre-eclampsia, classroom and class. All-round communication and communication, timely understanding of denuclearizing dynamics and effective feedback and intervention (as shown in Figure 1).

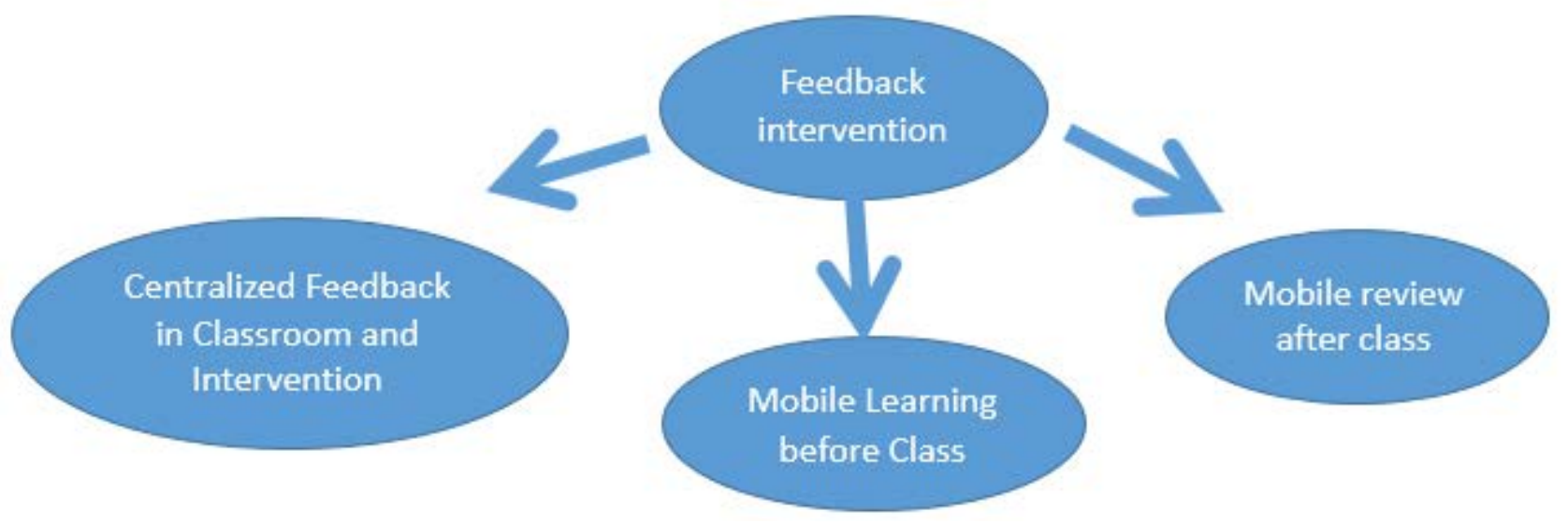

Figure 1. Bidirectional monitoring of mobile learning

In order to ensure the continuity of collaborative learning environment in time and space and the timeliness of interaction, we should pay attention to formative evaluation, and quantify denuclearizing attitudes and behaviors in their daily life, which, to a certain extent, stimulates students' learning enthusiasm and effectively helps freshmen to realize the change of their learning subjectivity.

3.2 Based on the characteristics of English subject, we should strengthen the mixing of teaching resources in mixed teaching to improve comprehensive quality and sustainable development ability in an all-round way.

The mixed teaching of mobile phone learning is flexible. The diversified teaching resources should be in line with "student-centered", "language learning rules as the essence" and "foreign language literacy as the grasp". The extensive teaching resources are not limited to textbooks. It is important to improve demonstrability to use English while organically integrating cultural education and quality education, so as to comprehensively improve students' comprehensive quality and sustainable development ability. In view of the mixed teaching mode of mobile learning, the attempt made by our school is to establish a public platform for Hatcheck. Students can join the platform for learning and communication by adding attention. Besides the communication between teachers and students, students can also interact with each other.

The diversified design of extracurricular mobile interactive activities is very important. Teachers should be good at discovering the shining points of each student, so that they can fully display themselves in the activities. At the same time, the integration of teaching resources should be "based on Vocational competence", subject to market orientation, according to social needs, starting from the ability needs of industries, job groups and posts, and combining with studentship specialties, to cultivate foreign language literacy and vocational competence in a coordinated manner, so as to improve students' soft skills in an all-round way. For example, in the semester of 2014-2015-2, the author made an attempt to teach mobile phone learning in class 14401 of Nanjing Communications 
Vocational and Technical College. Considering that students are computer majors, in order to guide students in mobile learning of smart phones, students are required to find practical apps for mobile phones and share them in English.

Students submit their assignments in a wide range of areas, including shopping APP (Yaobang/Haiti/Lei Tan), making friends APP (QQ/We Chat/Facebook), entertainment life APP (Bligh/The One/All K Song/Touch Ba Telephone/Super Course Sheet/Driving Examination Paper), English learning APP such as Bacchic, Anshan Chiba and English interesting dubbing, involving specialties such as 360 Cloud Disk, CAD Brief and WPS Office, counter-measures. It reflects extensiveness interests and diverse needs (as shown in Figure 2).

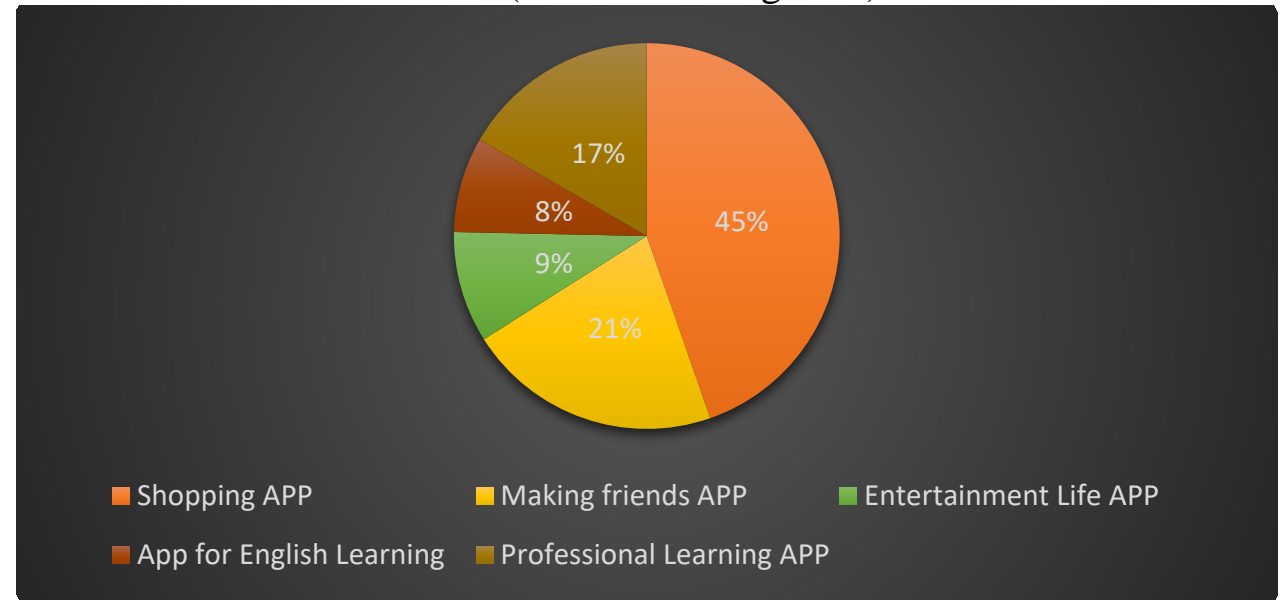

Figure 2. Mobile Learning Classification of Studentship App

Students have formed the habit of mobile learning, and in the selection of mixed learning resources and learning information retrieval and organizational ability, language use and expression ability and software operation ability have been improved to varying degrees, especially some students can learn dynamic video software to show, comprehensive quality and sustainable development ability has been greatly improved.

\section{Conclusion}

The research of Hybrid Teaching Mode in mobile learning environment follows the development trend of information-based teaching, and guides students to use smart phones reasonably and efficiently, play in middle school and learn to play. Through strengthening feedback and intervention in the whole process of learning, learning autonomy is gradually fostered. In the mobile learning environment created by mobile phones, multiple teaching resources exercise sustainable development ability. At the same time, teachers' acclimatization level in mixed teaching has been improved. Smart phones have shortened the distance between teachers and students, and teachers have grown up in the interaction with students.

\section{Acknowledgements}

Supported by: The approved project approved by "Foreign Language Teaching Reform Project" Phase II of the Steering Committee for Foreign Language Teaching in Vocational Colleges, the Ministry of Education.

The title of the project: "Research of Blended Teaching of Public English in Higher Vocational Colleges Based on Mobile Terminal".

The project number: 2018TX0016A. 


\section{References}

[1] Wang Kan. Promoting Vocational Education Reform and Innovation by Educational Acclimatization - Interpretation of the Ten-Year Development Plan of Educational Acclimatization (2011-2020) [J]. China's Educational Acclimatization. Higher Vocational Education, 2012 (27): 4-7.

[2] 35th CNNIC Report: Development of Internet in China [EB/OL]. HTTP://news.driver.com/1/381/381898.HTML, 2015-2-3.

[3] Mobile phones and teachers, who can catch the attention of College students? HTTP://WWW.NeWSes.com.c/due/2014/06/09/320005.HTML.2014-6-9.

[4] Li Deng. Current Situation and Analysis of Informal Learning of College Students under Information Technology Environment [D]. Wuhan: Central China Normal University, 2013:18

[5] Bork Kan. New Development of Educational Technology Theory from the Perspective of Mixed Learning [J]. Research on Audiovisual Education, 2004 (3): 3-4 